\title{
An Evaluation of Standby Losses Effect in Power Demand in Greek Urban Households
}

\author{
Stavros Dimitrios Kaminaris, George Christos Ioannidis and Constantinos Stavros Psomopoulos \\ Department of Electrical Engineering, Piraeus University of Applied Sciences, Egaleo 12244, Greece
}

Received: February 03, 2015 / Accepted: March 27, 2015 / Published: May 31, 2015.

\begin{abstract}
Standby consumption is a global phenomenon because the largest "leakers" are internationally-traded appliances usually line-powered electronic equipment. Currently, it represents 5\%-11\% (depending on the region and related estimations) of the total electricity demand in European households, mostly concentrated in entertainment and office equipments. This paper is focused on the evaluation of the standby losses in typical urban areas of Greece. The results of an analytical survey in urban households located in different areas of region of Attica-Greece are presented and analyzed. This survey is taking under consideration the type and the quantity of electric/electronic devices used, power consumption measurements concerning different standby modes of operation as well as people's habits in relation to the way they used the devices. Furthermore, recent and old detailed power consumption measurements of the most common modes of operation (on, off and standby), in other member states of Europe are presented and analyzed giving the opportunity to compare the situation in a typical urban Greek area and the respective in other parts of Europe. The presented data reveal the magnitude of the standby losses problem in Greece and the potential benefits gained by the enforcement of recent EU (European Union) policies.
\end{abstract}

Key words: Standby losses, field survey, consumption measurements, urban households.

\section{Introduction}

In recent years, the increase in energy consumption from appliances not being used for their primary purpose (or in "standby" mode) has become a major concern $[1,2]$. Even though this energy consumption could be easily considered negligible for a single device, when the millions of appliances installed around world are considered, and the fact that, this energy is consumed continuously, it can no longer be neglected. Currently, it represents 5\%-11\% (depending on the region and related estimations) of the total electricity demand in European households (excluding electric space heating and electric hot water preparation), mostly concentrated in entertainment and office equipment [3-6], studies from other parts of the world tend to show similar results [7-16].

Corresponding author: Stavros Dimitrios Kaminaris, professor, research fields: power systems, energy efficiency, electrical installations, intelligent systems and sustainable energy systems. E-mail: skamin@teipir.gr.
EU (European Union) through the EcoDesign Directive has launched studies in order to determine the magnitude of these losses as well as the reduction potential and the related policies to determine them. In December 2008, the EU Commission adopted the EC (Commission Regulation) No 1275/2008 [17] referring to standby and off-mode electric power consumption, targeting to a reduction of $35 \mathrm{TWh}$ in 2020 . The term "standby losses" describes better the presented situation because of the electricity consumption of electronic devices, while "off" or in a powered down state, and nowadays, it is the most accepted, as these electric loads have been labeled in literature as "vampire", parasitic or simply leaking electricity [1-6].

"Standby power" is associated with the operational mode of an appliance [18]. There are several different operational modes of an electrical/electronic appliance [18]. Any electrical/electronic appliance can be either connected (plugged) or disconnected (unplugged) from the mains. When disconnected, the appliance is 
drawing zero electrical power. If an appliance is connected to the mains, then, it can be ON or OFF as determined by the state of the electrical switch. If an appliance is connected to a power source and the power source switch is off then the appliance is in "OFF" state and draws zero power.

An appliance switched off at its power button and connected to a switched on power source can be in one of two modes: hard-off or soft-off. The placement of the power switch in an appliance determines if a switched off appliance has a hard-off or soft-off mode. If a mechanical power switch is placed between the power source and the internal power supply circuit, the appliance has a hard-off mode and in this mode an appliance does not consume power. However, if a mechanical power switch in an appliance is placed between the internal power supply circuit and the rest of the electronic/electrical circuits that make up the appliance, then the appliance has a soft-off mode. An appliance with a soft-off mode consumes power even when the appliance is switched off, at its power button, because of the current flowing into the appliance power supply from the mains. In this mode of operation, also known as OFF-mode, the appliance cannot be switched "on" by the consumer.

A switched "ON" appliance can be in active or standby mode. In active mode, the appliance is said to be in normal use, performing its primary function, and can be expected to draw up to the maximum power specified by the manufacturer. In standby mode, an appliance can either be in standby passive or standby active mode [18]. An example of standby passive mode is an appliance waiting to be switched on by a remote control or waiting to receive information thus maintaining device memory function, or displaying of time. If an appliance is performing an additional support function that is not its primary function, such as the downloading of software updates in the case of digital satellite decoders, then it is in standby active mode.

Standby mode is defined as the lowest power consuming mode which can not be switched off (influenced) by the user and that may persist for an indefinite time when the appliance is connected to the main electricity supply and used in accordance with manufacturer's instructions [19]. Standby power is the average power in standby mode [19]. In this work, the power that appliances consume while in soft-off, standby passive or standby active mode is considered standby power as also defined by Meier, et al. [20].

Standby power consumption can be a direct result of or a combination of the following [2, 21]:

- poor power supply design;

- memory retention function;

- internal clocks;

- displays (LED's/LCD);

- battery charging;

- instant on or remote control capability.

Summarizing the foregoing the following definitions regarding standby power are commonly used:

- off-mode: When a product or appliance is connected to a power source but does not produce any sound or picture, transmit or receive information or is waiting to be switched "on" by the consumer. If the product has a remote control, it can not wake up from it from off-mode. While the product may be doing some internal functions in off mode (e.g., memory functions, electromagnetic compatibility filters) these are not obvious to the user;

- passive standby: When a product or appliance is not performing its main function but is ready to be switched on (in most cases with a remote control) or is performing some secondary function (e.g., has a display or clock);

- active standby: It is mostly applicable to DVDs, VCRs and some stereo equipment where operation involves some mechanical drive (DVD and CD players). Active standby is the state at which the appliance is on but not performing its main function. For example, the DVD may be on but is not playing or recording.

Household standby consumption was the subject of many surveys and measurements in the last decade. 
The best of them have been used by EU, USA Department of Energy, Japan, Canada and IEA (International Energy Agency), in order to evaluate the standby losses and to determine the potential for reducing them [1-6, 8-16, 22-30].

The fact that energy labels and a few minimum energy performance standards have been introduced in the EU, in the last 15 years, has increased the sales of more energy efficient appliances. On the other hand, the number of electrical and electronic loads which are connected to the alternative current supply, typically all the time, has also been increased. The IEA estimated that, even with a continuation of all existing appliance policy measures, the appliance electricity consumption will grow by $25 \%$, from 2000 to 2020 (Fig. 1) [22].

From Fig. 1, it is evident that, the fastest growing electricity demand is projected to be standby/off-mode power consumption. This is the electricity consumption by appliances which are turned "off" or, are in a low power consumption mode. Although, the EU directive concerning the EcoDesign requirements has been launched in 2008 [17], there is an important potential saving which would be achieved reducing standby losses. Here it must be stressed out that, the directive 2010/30/EU on energy labels adopted by the EU in
2010 support and enhance the consumers' information on energy consumption. Energy labels help consumers choosing products which save energy and thus money. They also provide incentives for the industry to develop and invest in energy efficient product design. The energy labels in electronic devices and especially in TV's, DVD players etc present also the standby consumption of the device, providing additional information to the consumers on this issue [31].

Towards increment of energy efficiency, the EU adopted in 2012 the directive 2012/27/EU on energy efficiency. This directive establishes a common framework of measures for the promotion of energy efficiency within the Union in order to ensure the achievement of the Union's 2020 20\% headline target on energy efficiency and to pave the way for further energy efficiency improvements beyond that date. All EU-28 countries are thus required to use energy more efficiently at all stages of the energy chain-from the transformation of energy and its distribution to its final consumption. The new directive will help remove barriers and overcome market failures that impede efficiency in the supply and use of energy and provides for the establishment of indicative national energy efficiency targets for 2020 [32].

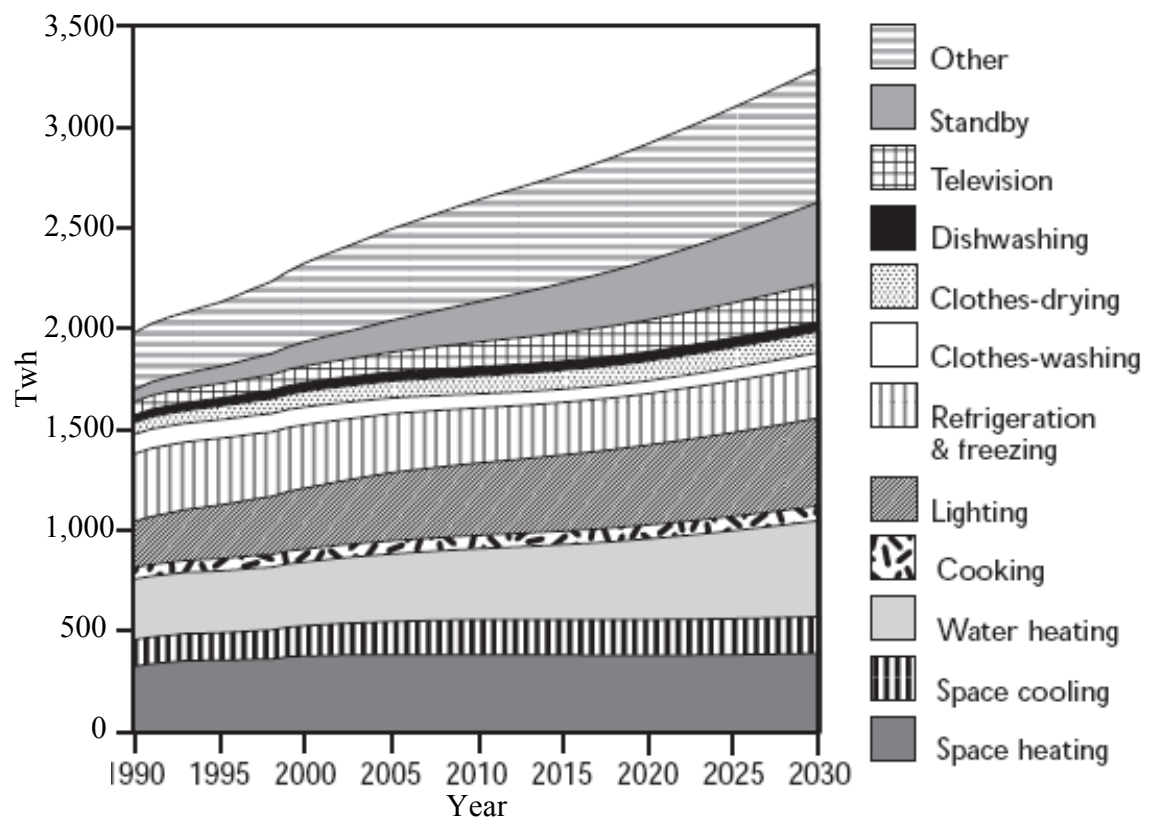

Fig. 1 Projected IEA residential electricity consumption by end-use with current policies (source: www.iea.org). 
This paper is focused on the evaluation of standby losses in typical urban households of Greece through an analytical survey, which was implemented successfully in 179 households located in different areas of region of Attica-Greece. Power consumption measurements, as well as the type and the quantity of electric/electronic devices used, are presented and analyzed. Also, the people's habits in relation to the use of devices were investigated, in order to estimate appropriate weighting factors with the help of which the contribution of different types of standby losses in the average standby loss the devices present will be evaluated. Furthermore, recent and old detailed power consumption measurements, of the most common modes of operation (on, off and standby), in other member states of Europe are presented and analyzed giving the opportunity to compare the situation in a typical urban Greek area and the respective in other parts of Europe. The European project SELINA [24] was the main source from which data were drawn. The presented data reveal the magnitude of the standby losses problem in Greece and the potential benefits gained by the enforcement of recent EU policies.

\section{Quantification Methods Used}

Generally speaking, various national studies conducted to estimate the standby losses at households, offices and stores, are based on field measurements and others are "bottom-up" estimates. In first case, measurements are conducted in a sample of representative households, offices or stores, in terms of saturation rate (ownership) or penetration rate of specific types of equipment and having average electricity consumption. Appliance saturation rate is a percentage that indicates the number of households in a given geographical area that own a specific appliance. Saturation levels reflect the ownership intensity of a specific appliance within a given geographical area. In case where every household owns a specific appliance saturation levels are said to be 100\%. Appliance penetration rates are used to indicate the total number of an appliance found in a specified population of households. Appliance penetration rates may exceed 1 in cases where there is more than one of each appliance per household.

On the other hand, for "bottom-up" estimates, standby losses of a wide range of individual appliances are measured separately in households, offices and stores, the average standby energy consumption is then multiplied by the number of those appliances sold in country. In the absence of actual measurements, calculations are based on standby power measurements of appliances reported in consumer magazines. The types of appliances taken into consideration for evaluating the total standby power losses are mostly the common ones found in almost all countries (audio and video equipment, telephony, kitchen appliances, office equipment, battery operated devices and miscellaneous home appliances).

The methods used in this work for quantifying the standby consumption in typical households located in urban areas of Greece involved both product measurements and bottom-up estimates.

\section{The Measurement System}

The measurements performed using a power meter SEM16+ which measures single phase loads up to $230 \mathrm{~V} / 16 \mathrm{~A}$. The SEM16+ is a measuring device to determine the electrical energy consumption costs for individual electrical single phase up to $16 \mathrm{~A}$ equipments in households. The SEM16+ starts automatically a $24 \mathrm{~h}$ measuring period after the unit to be tested has been plugged in. After completion of the measuring period the energy consumption and the energy costs for the period will be displayed. The period of the measuring can be changed to 1,7 or 30 days and manually started and stopped. During and after completion of measuring the results of power, costs per year, energy consumption, costs and equivalent $\mathrm{CO}_{2}$ consumption at the measuring period, voltage, frequency, current, idle power, apparent power, phase shift, power factor, minimum and maximum 
Table 1 Technical characteristics of the used power meter SEM16+.

\begin{tabular}{ll}
\hline \multicolumn{2}{l}{ Technical characteristics } \\
\hline Input voltage & $230 \mathrm{~V}$ alternative current $\pm 10 \%, 50 / 60 \mathrm{~Hz}$ \\
Max. load & $16 \mathrm{~A}, 3,680 \mathrm{~V} \mathrm{Ar}$ \\
Measuring range & $0.1-3,680 \mathrm{~W}$ \\
Precision & $1 \%, \pm 1$ digit \\
Protection class & $\mathrm{IP} 20$ \\
\hline
\end{tabular}

power can be called. Table 1 shows the main technical characteristics of the power meter used.

\section{Methodology of the Survey}

\subsection{Definitions and Basic Concepts}

For the selection of the sample, the collection of information and the tabulation of data, certain concepts were adopted and are being clarified as follows:

- Household is defined as either one person living alone or a group of persons, not necessarily related, living at the same address with common housekeeping. The household members share the expenses of household or benefit from them due to lack of income. As necessary prerequisite to be included the household in the survey, is the existence of, at least, one member aged 16-74;

- Urban area: Municipal communities with 10,000 inhabitants or more.

\subsection{Coverage}

The survey covers all the private households in urban areas in region of Attica-Greece, irrespective of their size or socio-economic characteristics. The following were excluded from the survey:

- institutional households of all types (boarding houses, elderly homes, hospitals, prisons, rehabilitation centers, camps, etc.);

- households with more than five lodgers and;

- households with foreigners serving in diplomatic missions.

\subsection{Time Coverage}

The period of the conducted survey was: 01/03/2013-30/09/2013.

\subsection{Data Collection}

The method of data collection is the PAPI (paper-assisted personal interview) and actual power measurements. A questionnaire was used to gather the following:

- demographic data \& user awareness;

- appliance penetration rate;

- appliance use time;

- appliance operational behavior: two types of questions were used in the questionnaire;

- open format;

- closed format.

\subsection{Appliance Penetration Rate Included in Survey}

The appliances included in the survey to determine penetration rates fall in three major categories: IT equipment (computer-desktop, computer-laptop, computer monitor (liquid crystal display), computer-speakers, scanners, printers-inkjet, printers-laserjet, multifunction devices, fax, cordless phone, modem-routers and digital photo-frames), audio-visual equipment $\&$ entertainment equipment (TV-thin-film-transistor/liquid crystal display, TV-cathode ray tube, DVD/VCR, set top boxes, home theatre systems, game consoles and stereo-integrated), cooking \& housework equipment (dish washers and dryers, washing machines, kitchen appliance and microwave/oven) and other (air-conditioner). The list of appliances is very similar to appliances listed in other surveys and measurements campaigns so that meaningful comparisons could be made on the data obtained.

\subsection{Consumer Appliance Operational Behavior}

One of the factors that determine the energy use in a specific household is the behavior of the residents. The questions in the survey were grouped in two major groups, appliances with and without remote controllers. Most remote controlled appliances do not have hard off switches provided on the appliances. In soft-off state, an appliance consumes very low levels of power and in 
a hard-off state appliance power consumption is zero.

\subsection{Appliance Use Times}

Appliance use time is the amount of time an appliance is in full operational mode.

Use time is another variable required to be established in order to be able to evaluate the total energy losses due to standby power losses. Standby energy losses depend on how long an appliance spends in the standby mode. The average daily hours of usage is the main determinant factor of appliance standby power consumption, especially because the actual measured power levels are not very high for most appliances. In the survey, the respondents were requested to estimate the average use time (\%) of the different appliances in the household on a weekday time.

\subsection{Sample Fraction}

The method used is a sampling survey and 179 households have been successfully interviewed, representing the $0.01 \%$ of total urban households in the region of Attica for the year as whole (sample fraction is $0.01 \%$ of $1,790,303=179$ questionnaires).

Moreover, the region of Attica area is divided into four sub-areas (four prefectures):

- prefecture of Athens;

- prefecture of east Attica;

- prefecture of west Attica;

- $\quad$ prefecture of Piraeus.

According to the EL.STAT (Hellenic Statistical Authority) survey [33], the total number of urban households at the region of Attica is 1,790,303 (almost $47 \%$ of total Greek urban households). In each of the above four prefecture the corresponding number of urban hh is:

- prefecture of Athens $=1,259,839$ (70.37\% of $1,790,303)$;

- prefecture of east Attica $=217,866$ (12.17\% of 1,790,303);

- prefecture of west Attica $=60,010(3.35 \%$ of $1,790,303)$;
- prefecture of Piraeus $=252,588 \quad(14.11 \%$ of 1,790,303);

Therefore, we collected successfully:

- prefecture of Athens $=126(70.37 \%$ of 179 questionnaires);

- prefecture of east Attica $=22(12.17 \%$ of 179 questionnaires);

- prefecture of west Attica $=6(3.35 \%$ of 179 questionnaires);

- prefecture of Piraeus $=25(14.11 \%$ of 179 questionnaires).

\subsection{Research Methodology}

The research methodology is made up of the following components:

- Appliance survey

By using the survey, it was possible to obtain data that was used for the estimation of household penetration levels of standby appliances. The survey was also being used to: estimate appliance use times, gain an insight into user appliance operational behavior, and gather some demographic data.

- Measurement of individual appliance standby power consumption

Measurement of individual appliance standby and full mode power consumption were carried out in the 179 successfully surveyed. A suitable power meter (SEM16+) that measured very low power levels, where current waveform distortions were present, was used for reliable results.

- Standby power consumption estimation

The results of measurements and appliance penetration survey are used as basic input data for estimating the household standby real power consumption. The estimated urban household standby power consumption is obtained by using an appropriate mathematical model presented below.

\section{Results and Discussion}

\subsection{Demographic Results}

As it was mentioned in the previous section, the 179 
successfully collected questionnaires are analyzed and the results are presented in Fig. 2.

Fig. 2 shows that the majority of the users (54.8\%) which participated in the survey are between 18 and 35 years old. Moreover, a high percentage of the participants have university education (37.9\%) while, $35.2 \%$ and $27 \%$ of them have technical vocational and elementary education, respectively.

The age-related distribution of the appliances, which are the participants possess and the criteria for purchase new appliances are presented in Fig. 3. Most of the appliances are 6-10 years old and a $31.1 \%$ of them are less than five years old. Furthermore, $27.5 \%$ of the appliances are B class and $41.6 \%$ are A class and above.

Furthermore, as it can be seen from Fig. 3c, the most important criterion is the price $(29.3 \%$ of the questionnaires) then the functionality of the device (27.2\%) and only $19 \%$ of the questionnaires purchase appliances based on their electric consumption.

\subsection{Mathematical Model for Estimation of Standby Power}

In every household (in the 179 successfully surveyed), measurements were recorded for all standby capable appliances found plugged in and drawing power in full, passive standby, active standby or in soft-off mode. In appliances where a standby mode was evident, the measurements were taken in the standby mode. Measurements were also done in all other low power appliance operational modes that could be effectively distinguished. Measurements in the full operational/active mode were taken while the appliance was set to user preferable settings.

The measurement results are presented for all pertinent operational modes found on the appliances. For each appliance, detail of the maximum, average, and minimum power consumption in all relevant operational modes are provided.

The parameters of interest in the estimation are:

- average appliance standby power consumption for each standby mode (W);

- average usage time percentage (\%) - (in absolute values) of an appliance device operation in off-mode or passive standby or active standby compared to its total standby time;

- appliance penetration rates (\%).

The mathematical equation that has been used to

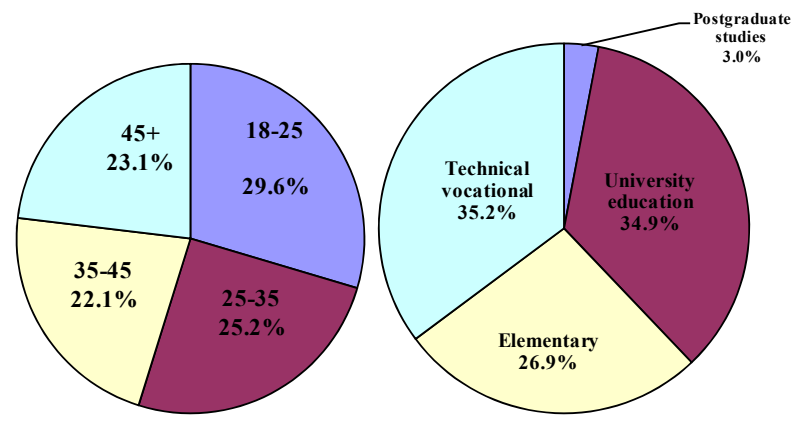

(a) (b)

Fig. 2 (a) Age of users; (b) education level of the users.

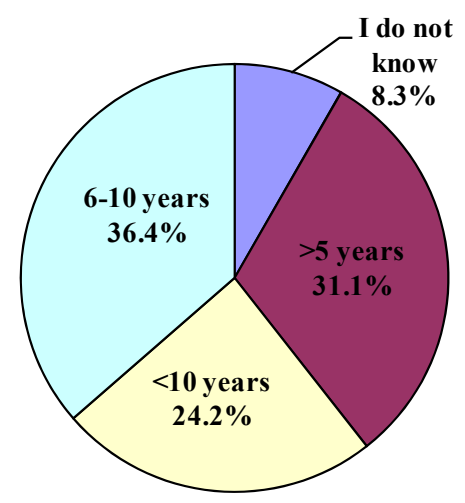

(a)

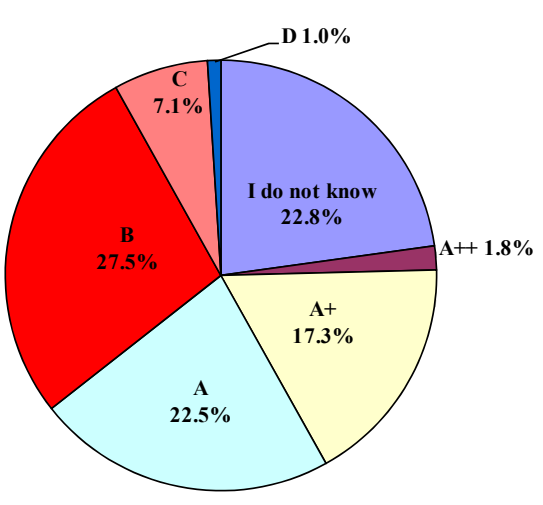

(b)

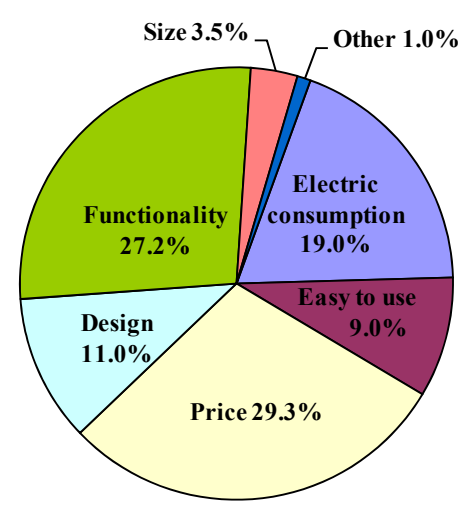

(c)

Fig. 3 (a) Age-related distribution of home appliances; (b) energy label of home appliances; (c) criteria of purchase of new home appliances. 
define TASPC (total appliance standby power consumption) of an appliance in a day is:

$\mathrm{TASPC}=\operatorname{Sum}(A S P C i \cdot$ Par $)$

$i=1$ (off-mode), 2 (passive standby), 3 (active standby).

where, ASPC $i$ : the average real power consumed in standby mode in Watts obtained for each appliance of interest from the measurements (taken into account also the average usage time percentage for each appliance in a day estimated from the survey — standby hours/day (\%)); Par: appliance penetration rate (\%).

\subsection{Appliance Standby Power Measurements and Analysis Results}

The bottom-up estimates are based on the type and number of devices used in 179 households (survey sample) in urban areas of region of Attica-Greece (including Athens and suburbs in a range of $50 \mathrm{~km}$ from Athens center). The average standby power use of household is calculated from a combination of field measurements, like the ones mentioned above and known appliance saturations. Based on the questionnaires used on the survey and measurements results, an estimation of the standby power consumption per urban household is attempted using the mathematical model presented previous (Table 2). These results are used further to evaluate, through projection, the magnitude of the standby power consumption in residential sector in Greece and by this the contribution in the annual electricity consumption of the country.

As it was mentioned in Section 4.8, standby measurements have been conducted successfully in these 179 urban households and the results can be shown in Table 2 and are visualized in Fig. 4. As it can be seen from Table 2 and Fig. 4, laptop and desktop computers present the highest standby consumption while stereos and printers follow. Also, appliances like set-top boxes and LCD TVs have low standby losses. These appliances have been widely used the last two to four years in Greek homes and are basically new technology devices in which manufacturers have implemented low energy consumption modules, conforming to the requirements of latest European standards. Furthermore, the standby losses of an average urban household, taking under consideration weighting factors in order to calculate the contribution of different types of standby losses has been estimated and is about $37.4 \mathrm{~W}$.

During October 2011-September 2012, the EL.STAT conducted for the first time, a survey on energy consumption in households, with which data have been collected on energy consumption by end-use (space heating-cooling, domestic hot water production, lighting, etc.) in the residential sector, as well as on quantities and type of fuels used [34]. According to the results of this survey, average annual electricity consumption per household in urban areas is $4,000 \mathrm{kWh}$.

This energy consumption corresponds to an average power consumption of about $456.6 \mathrm{~W} / \mathrm{h}$, considering $8,760 \mathrm{~h}$ per year. Therefore, the average standby consumption of an average Greek urban household corresponds to about $8.2 \%$ of the respective total average power consumption. These results seem to be in accordance with the findings of other studies. In particular, the existing studies for estimating the standby consumption are focus on household appliances and mainly in electronic appliances. Up to now, several estimations for the contribution of the standby consumption in residential have been produced, indicating the magnitude of the losses. Studies in Germany, Denmark, the Netherlands and the US have found that, standby power accounts for as much as $10 \%$ of national residential electricity use [1-6, 15, 22, 24, 27, 35]. Estimations of standby power consumption in the EU, as it is already mentioned before, showed that it corresponds up to $11 \%$ of total residential electricity consumption [1-6, 24]. Case studies of individual homes have been reported for houses in Sweden, France, UK, Japan, the US, China, Canada, Argentina and New Zealand [4, 7-16, 23, 26-29, 35-38]. Standby 
Table 2 Survey measurements of the standby and off-mode power demand in urban households appliances.

\begin{tabular}{|c|c|c|c|c|c|c|c|c|c|c|c|c|}
\hline \multicolumn{13}{|c|}{ Standby and off-mode power consumption in (W) } \\
\hline \multirow[b]{2}{*}{ Category } & \multirow[b]{2}{*}{ Units } & \multirow[b]{2}{*}{$\begin{array}{l}\text { Number } \\
\text { of } \\
\text { devices }\end{array}$} & \multirow[b]{2}{*}{$\begin{array}{l}\text { Penetratio } \\
n \text { rate }(\%)\end{array}$} & \multirow[b]{2}{*}{$\begin{array}{l}\text { Standby } \\
\text { hours/day } \\
\text { (h) }\end{array}$} & \multirow[b]{2}{*}{$\begin{array}{l}\text { Standby } \\
\text { hours/day } \\
(\%)\end{array}$} & \multicolumn{2}{|l|}{ Off mode } & \multicolumn{2}{|l|}{$\begin{array}{l}\text { Passive standby } \\
\text { (sleep mode) }\end{array}$} & \multicolumn{2}{|c|}{$\begin{array}{l}\text { Active standby } \\
\text { (On) }\end{array}$} & \multirow[b]{2}{*}{$\begin{array}{l}\text { Average } \\
\text { standby power } \\
\text { (W) }\end{array}$} \\
\hline & & & & & & $\begin{array}{l}\text { Off mode time } \\
\text { /total standby } \\
\text { time }(\%)^{*}\end{array}$ & Average (W) & $\begin{array}{l}\text { Passive standby } \\
\text { time } \\
\text { /total standby } \\
\text { time }(\%)^{*}\end{array}$ & $\begin{array}{l}\text { Average } \\
\text { (W) }\end{array}$ & $\begin{array}{l}\text { Active } \\
\text { standby } \\
\text { time/total } \\
\text { standby time } \\
(\%)^{*}\end{array}$ & Average $(\mathrm{W})$ & \\
\hline \multirow{12}{*}{ IT equipment } & Computer, desktop & 81 & 45 & 18 & 75 & 80 & 2.7 & 10 & 26.1 & 10 & 33 & 2.7 \\
\hline & Computer, laptop & 93 & 52 & 18 & 75 & 80 & 1.2 & 10 & 8.7 & 10 & 21.2 & 1.5 \\
\hline & Computer monitor (LCD) & 81 & 45 & 18 & 75 & 80 & 1.35 & 10 & & 10 & 9.2 & 0.7 \\
\hline & Computer-speakers & 67 & 37 & 18 & 75 & 80 & 2.1 & & & 20 & 3.6 & 0.7 \\
\hline & Scanners & 28 & 16 & 24 & 99 & & & 90 & 2.5 & 10 & 9.5 & 0.5 \\
\hline & Printers, inkjet & 49 & 27 & 24 & 98 & 90 & 1.9 & & & 10 & 4.6 & 0.6 \\
\hline & Printers, laserJet & 45 & 25 & 24 & 98 & 98 & 0.2 & 10 & 10.4 & 10 & 13.5 & 0.6 \\
\hline & Multifunction devices & 45 & 25 & 23 & 97 & 90 & 3.4 & & & 10 & 7.8 & 0.9 \\
\hline & Fax & 27 & 15 & 24 & 98 & & & 100 & 5.8 & & & 0.9 \\
\hline & Cordless phone & 117 & 65 & 23 & 96 & & & 95 & 2.4 & 5 & 3.3 & 1.5 \\
\hline & Modem-routers & 130 & 73 & 18 & 75 & 10 & 1.7 & & & 90 & 9.2 & 4.6 \\
\hline & Digital photo-frames & 49 & 27 & 24 & 99 & 5 & 0.2 & 95 & 1.1 & & & 0.3 \\
\hline \multirow{7}{*}{$\begin{array}{l}\text { Audio/Visual \& } \\
\text { Entertainment } \\
\text { equipment }\end{array}$} & TV, TFT/LCD & 261 & 146 & 16 & 65 & 10 & 0.4 & 90 & 4.7 & & & 4.0 \\
\hline & TV, CRT & 54 & 30 & 16 & 65 & 50 & 0 & 50 & 3.4 & & & 0.3 \\
\hline & $\mathrm{DVD} / \mathrm{VCR}$ & 170 & 95 & 23 & 96 & 15 & 1.6 & 80 & 1.5 & 5 & 5.8 & 1.6 \\
\hline & Set top boxes & 75 & 42 & 16 & 65 & & & 100 & 0.7 & & & 0.2 \\
\hline & Home theatre systems & 24 & 13 & 22 & 92 & 90 & 2.8 & 5 & 6.5 & 5 & 11.7 & 0.4 \\
\hline & Game consoles & 58 & 32 & 23 & 96 & 90 & 0.7 & 5 & 3.8 & 5 & 7.5 & 0.4 \\
\hline & Stereo, integrated & 130 & 73 & 22 & 92 & 75 & 0 & & & 25 & 6.2 & 1.0 \\
\hline \multirow{4}{*}{$\begin{array}{l}\text { Cooking \& } \\
\text { Housework } \\
\text { equipment }\end{array}$} & Dish washers and dryers & 113 & 63 & 23 & 94 & 75 & 0 & & & 25 & 6.1 & 0.9 \\
\hline & Washing machines & 177 & 99 & 21 & 88 & 95 & 1.5 & & & 5 & 4.6 & 1.4 \\
\hline & Kitchen appliance & 169 & 94 & 24 & 99 & 95 & 3.7 & 5 & 4.8 & & & 3.5 \\
\hline & Microwave, oven & 90 & 50 & 22 & 92 & 95 & 0.2 & & & 5 & 7.3 & 0.3 \\
\hline \multirow[t]{3}{*}{ Air conditioners } & Air-conditioners & 192 & 107 & 20 & 83 & 10 & 1.4 & 90 & 9.5 & & & 7.7 \\
\hline & & & & & & & & & & & Total & 37.4 \\
\hline & & & & & & & & & & & & $8.2 \%$ \\
\hline
\end{tabular}

"Weighting factor at off-mode or passive standby or active standby is the usage time percentage (in absolute values) of a device operation in off-mode or passive standby or active standby compared to its total standby time. 




Fig. 4 Off mode, passive standby and active standby measurements.

power ranged from $70 \mathrm{~W}$ to $125 \mathrm{~W}$, but even though the examined homes were similar to the representative ones in each country, in some cases this important parameter could not be retained. In Japan, the ECCJ (Energy Conservation Centre) estimated that the standby consumption was $308 \mathrm{kWh} /$ year or $7.3 \%$ of the power consumption of a whole house [23, 28]. A very detailed study in Australia showed that the household standby power consumption averaged $87 \mathrm{~W}$, and energy consumption averaged $760 \mathrm{kWh} /$ year or $11.6 \%$ of the household total energy consumption [11, 14].

As it can be seen from the survey measurements presented in Table 2, the domestic appliances used are presenting low power consumption in standby "off mode" and "passive mode". In some cases (home theatre, digital photo-frames), the consumption is very low, below $1 \mathrm{~W}$, while in others the results are not that low. If these results are compared with the ones presented in Table 3, the similarities can be easily revealed.

Table 3 presents measurements performed in new equipment produced under the most recent EU studies about standby consumption and as it can be seen the results are similar to the ones measured in urban areas of region of Attica-Greece. The similarity can be easily ascribed to the fact that the measured equipment is appeared with a delay of 1-2 years in the Greek market. This delay of entering the appliances into the market 
Table 3 Power demand at "off mode" and "passive mode" as it was measured during the SELINA project.

\begin{tabular}{lll}
\hline $\begin{array}{l}\text { Power consumption in watts } \\
\text { (W) }\end{array}$ & $\begin{array}{l}\text { "Off mode" } \\
\text { average }\end{array}$ & $\begin{array}{l}\text { "Passive } \\
\text { mode" } \\
\text { average }\end{array}$ \\
\hline Computer-laptop & 0.5 & 0.85 \\
Computer monitor & 0.5 & 1.97 \\
Computer, desktop & 1.5 & 5.43 \\
Digital photo frame & 0.6 & 3.74 \\
DVD/VCR & 1.8 & 2.09 \\
Microwave & 0.2 & 1.87 \\
Phone, cordless-base station & 0.1 & 1.2 \\
Radio & 0.9 & 1.79 \\
Set-top box & 0.2 & 4.07 \\
Computer-speakers & 1.8 & 3.92 \\
Stereo, integrated & 0.8 & 4.89 \\
TV, CRT & 0.0 & 3.51 \\
TV, LCD & 0.3 & 1.04 \\
Microwave, oven & 0.1 & 1.87 \\
Speaker, powered & 1.4 & 1.77 \\
\hline
\end{tabular}

is responsible for the improved characteristics they exhibit and consequently, the lower standby consumption. Furthermore, considering the consuming characteristics of the users it can also be seen that, one important parameter is the energy consumption as well as the price of a domestic appliance. Based on these facts, it is obvious that, the equipment which is bought and in use, in the average representative Greek urban household, is usually in accordance with the newer standards.

Table 4 presents the number of households in urban areas per Greek region and (taking into account the estimated standby power through this survey) the estimated corresponding power demand required to cover standby losses. The number of houses corresponds only to the areas that are considered as urban, while, a significant number of houses in some suburbs near cities are not included as these areas are not considered as a part of the urban area. Even though the houses are located in regions with different population density and profile, it was considered that, the average power consumption in standby mode, should not present significant differences, due to the fact that value was a weighted average considering the appliances installed on an average representative house.
Table 4 Estimations of the standby power demand per region in Greece $\left({ }^{*}\right)$.

\begin{tabular}{lll}
\hline Regions of Greece & $\begin{array}{l}\text { Households in urban } \\
\text { areas }\end{array}$ & $\begin{array}{l}\text { Standby power } \\
(\mathrm{MW})\end{array}$ \\
\hline Thrace & 89,517 & 3.35 \\
Attica & $1,790,303$ & 66.94 \\
Crete & 162,467 & 6.07 \\
Macedonia & 817,819 & 30.58 \\
Epirus & 73,691 & 2.76 \\
Ionian Islands & 42,112 & 1.57 \\
Aegean Islands & 151,351 & 5.66 \\
Peloponnesus & 291,089 & 10.88 \\
Central Greece & 215,371 & 8.05 \\
Thessaly & 205,507 & 7.68 \\
Total & $3,839,227$ & 143.57 \\
According data & of EL.STAT for the number of urban \\
households. & &
\end{tabular}

Based on that, Table 4 represents the estimated electricity demand in order to support standby consumption, only for the houses in urban areas. The presented estimated values are rather high for the considered number of houses and thus, require a significant percentage of the power generation, especially in the island regions, where the power production depends on small diesel power stations, with limited support by renewable electricity sources. If the devices in standby mode operating in other types of buildings, or in houses excluded in this study are added, it can be easily concluded that, the required electricity produced by the power stations is even higher. Nevertheless the magnitude of standby losses per household is expected to be slightly reduced. This is based on the fact that the new appliances entered into the market are forced to present significant low standby losses, and due to the gradually change in Greek consumers' behavior towards adopting more energy efficient profile, and choosing devices that presents as low as possible energy and standby losses.

As it can be seen by Table 4, the standby power consumption in Greece seems to be almost 144 MW. This value can not be neglected if it is compared with the installed capacity of several power stations of Greece, mainly lignite power plants, where the typical unit capacity lies between $200 \mathrm{MW}$ and $350 \mathrm{MW}$ [39]. 
It is more than obvious that, a reduction of this power demand could lead to the reduction of the base load of the Greek electricity grid, resulting consequently in a reduction of lignite consumption (basic fuel of the Greek power sector covering almost $45 \%-50 \%$ of the electricity production). If transmission and distribution losses are also considered, the benefits are even higher due to the fact that the Greek electricity network presents losses equal to $7 \%-8 \%$ of the consumption.

It is obvious that, specific policy actions focusing on informing people should be started in order to reduce these magnitudes and power demand of the network at the same time. Also, based on the fact that this will result in reduced electricity consumption bills, it will be an important motivation for electricity end users, especially nowadays where the economic crisis in Greece results in a significant reduction of the household income.

\section{Conclusions}

The results of the measurements showed that, the average standby consumption per household in urban areas in Greece as a percentage of the respective average electricity consumption is about $15 \%$ higher than the estimated values for other EU and developed countries. Although this is true, the present standby losses in Greek urban households (37.4 W) are among the lowest in EU, mainly due to the fact that the Greek household appliances market presents a "delay" to offer different types of equipment. On the other hand, this fact gave the advantage that the equipment in the Greek market is already conformed to the new more strict rules about energy efficiency. Nevertheless, in Greece, the power demand of appliances in standby mode is high and in country scale exceeds $140 \mathrm{MW}$. The results of the survey show that the people in urban areas are starting to consider the energy efficiency as an important parameter, after the price and the functionality which are considered the most important criteria for selection up to now. All these facts as well as the new strict regulations adopted by the EU seem to result to a reduction in the standby consumption in EU and consequently in Greece in the near future.

\section{References}

[1] Bertoldi, P., Aebischer, B., Edlington, C., Hershberg, C., Lebot, B., and Lin, J. 2002. Standby Power Use: How Big Is the Problem? What Policies and Technical Solutions Can Address It? California: Lawrence Berkeley National Laboratory. Accessed May 20, 2010. http://www.escholarship.org/uc/item/6xm6k7wg.

[2] IEA (International Energy Agency). 2001. "Things That Go Blip in the Night: Standby Power and How to Limit it." IEA. Accessed May 20, 2010. http://www.iea. org/textbase/nppdf/free/2000/blipinthenight01.pdf.

[3] Bertoldi, P. 2004. The Consumer Electronics Energy Consumption and the European Policies to Reduce it. Final report. Accessed May 20, 2010. http://energyefficiency.jrc.cec.eu.int.

[4] IEE (Intelligent Energy Europe). 2008. "Residential Monitoring to Decrease Energy Use and Carbon Emissions in Europe." Remodece Project No. EIE/05/124/SI2.419657. Accessed June 15, 2010. http://www.isr.uc.pt/ remodece.

[5] Fraunhofer Institute for Reliability and Microintegration. 2007. EuP (Energy using Product) Preparatory Study Lot 6 Standby and Off-Mode Losses. Final report. Accessed June 15, 2010. http://www.ecostandby.org/documents. php.

[6] EuP (Energy using Product) Preparatory Study Lot 26. 2011. "Networked Standby Losses." TREN/D3/91-2007/ Lot 26. Accessed June 15, 2011. http://www. ecostandby.org.

[7] APPCDC (Asia-Pacific Partnership on Clean Development and Climate). 2008. International Initiatives to Track Standby Power Consumption: Evaluation and Verification. Final report. Accessed May 20, 2010. http://www.energyrating.gov.au/standby.

[8] Chen, S., Yoshino, H., Levine, M. D., and Li, Z. 2009. "Contrastive Analyses on Annual Energy Consumption Characteristics and the Influence Mechanism between New and Old Residential Buildings in Shanghai, China, by the Statistical Methods.” Energy and Buildings 41 (12): 1347-59.

[9] Firth, S. K., Lomas, K. J., Wright, A. J., and Wall, R. 2008. "Identifying Trends in the Use of Domestic Appliances from Household Electricity Consumption Measurements." Energy and Buildings 40 (5): 926-36.

[10] Fung, A. S., Aulenback, A., Ferguson, A., and Ugursal, V. I. 2003. "Standby Power Requirements of Household Appliances in Canada." Energy and Buildings 35 (2): 217-28. 
[11] Harrington, L., and Kleverlaan, P. 2001. Residential Standby Power Consumption in Australia, Project for the National Appliance \& Equipment Energy Efficiency Committee. Australian Greenhouse Office Final report.

[12] McAllister, J. A., and Farrell, A. E. 2007. "Electricity Consumption by Battery-Powered Consumer Electronics: A Household-Level Survey.” Energy 32 (7): 1177-84.

[13] Meier, A., Lin, J., Liu, J., and Li, T. 2004. "Standby Power Use in Chinese Homes." Energy and Buildings 36 (12): 1211-6.

[14] NAEEEP (National Appliance \& Equipment Energy Efficiency Program). 2003. Report 2003/04: Appliance Standby Power Consumption Store Survey 2003. Final report. Accessed June 15, 2010. http://www.energyrating. gov.au/library/pubs/200304-storesurvey.pdf.

[15] Ross, J. P., and Meier, A. 2002. "Measurements of Whole-House Standby Power Consumption in California Homes." Energy 27 (9): 861-8.

[16] Tanides, G. 2008. "Estimation of Stand-By Energy Consumption and Energy Saving Potential in Argentine Households." Energy for Sustainable Development XII (4): 76-88.

[17] EC (EU Commission Regulation) No 1275/2008. 2008. "Implementing Directive 2005/32/EC with Regard to Ecodesign Requirements for Standby and Off Mode Electric Power Consumption of Electrical and Electronic Household and Office Equipment." EU Official Journal L339 (December): 45-52.

[18] Mercy, V. S. 2009. "Estimation of Standby Power and Energy Losses in South African Homes." Ph.D. thesis, University of the Witwatersrand.

[19] IEC (International Electrotechnical Commission)/TC 59. 2005. Household Electrical Appliances Measurement of Standby Power. Technical report IEC 62301.

[20] Meier, A. K., Huber, W., and Rosen, K. 1998. "Reducing Leaking Electricity to 1 Watt." Presented at the ACEEE (American Council for an Energy-Efficient Economy) Summer Study on Energy Efficiency in Buildings, Pacific Grove California, USA.

[21] Mohanty, B. 2001. "Standby Power Losses in Household Electrical Appliances and Office Equipment." Presented at the Regional Symposium on Energy Efficiency Standards and Labelling, Paris, France.

[22] IEA (International Energy Agency). 2003. Cool Appliances-Policy Strategies for Energy Efficient Homes. Paris: IEA. Accessed June 15, 2010. http://www.iea.org/textbase/nppdf/free/2000/cool_applia nce2003.pdf.

[23] Ijuin, T. 2000. "Approach to Reduce Standby Power in Japan." Agency of Natural Resources and Energy. Accessed June 20, 2010. http://www.enecho.meti. go.jp/english/index.htm.
[24] IEE (Intelligent Energy Europe). 2010. “Standby and Off-Mode Energy Losses in New Appliances Measured in Shops.” SELINA Project No. IEE/07/563/SI2.499206. Accessed June 15, 2010. http://www.selina-project.eu/index.cfm.

[25] IEA (International Energy Agency). 2005. "Standby Power Use and the IEA "1-Watt Plan"-Fact Sheet." IEA. Accessed May 20, 2010. http://www.iea.org/papers/2005/standby_fact.pdf.

[26] Lehtomäki, E. 2010. Consumption Figures of Electric Appliances. Helsingin Energia report. Accessed June 15, 2010. http://www.helen.fi/pdf/consumption.pdf.

[27] Nordman, B., Siderius, H. P., Harrington, L., Ellis, M., and Meier, A. 2009. "Network Connectivity and Low-Power Mode Energy Consumption.” In Proceedings of the 5th Int. Conf. on Energy Efficiency in Domestic Appliances and Lighting, 1091-101.

[28] Ueno, T., Tsuji, K., Inada, R., and Saeki, O. 2005. "Effectiveness of Displaying Energy Consumption Data in Residential Houses Analysis on How the Residents Respond." In Proceedings of the ECEEE 2005 Summer Study —What Works \& Who Delivers? 1289-99.

[29] Valentova, M., and Knapek, J. 2009. "Myths and Facts on Standby Power Energy Saving Potential-Czech Republic Case Study." In Proceedings of the 10th IAEE European Conference on Energy, Policies and Technologies for Sustainable Economies, 1-13.

[30] European Union. 2005. "Green Paper on Energy Efficiency or Doing More with Less." European Union. Accessed September 14, 2010. http://www.europeanenergyforum.eu.

[31] European Union. 2010. Directive 2010/30/EU of the European Parliament and of the Council of 19 May 2010 on the Indication by Labelling and Standard Product Information of the Consumption of Energy and Other Resources by Energy-Related Products (Text with EEA Relevance). OJ L 153, 18.6.2010. 1-12.

[32] European Union. 2012. Directive 2012/27/EU of the European Parliament and of the Council of 25 October 2012 on Energy Efficiency. Amending Directives 2009/125/EC and 2010/30/EU and Repealing Directives 2004/8/EC and 2006/32/EC Text with EEA Relevance. OJ L 315, 14.11.2012. 1-56.

[33] Hellastat. 2011. "Population Survey." Hellenic Statistical Authority. Accessed May 15, 2010. http://www.statistics.gr.

[34] Hellastat. 2011-2012. "Survey on Energy Consumption in Households." Hellenic Statistical Authority. Accessed June 20, 2010. http://www.statistics.gr.

[35] ACEEE (American Council for an Energy Efficient Economy). 2004. "1-Watt Standby Power for Home Appliances.” ACEEE. Accessed June 20, 2010. 
http://www.aceee.org/pubs/a042_a1.pdf.

[36] Blok, K. 2005. "Enhanced Policies for the Improvement of Electricity Efficiencies.” Energy Policy 33 (13): 1635-41.

[37] EEB (Energy Efficiency Branch). 2009. "Regulatory Impact Statement for Standby Power Consumption.” Ministry of Energy, Mines and Petroleum Resources, BC (British Columbia) Province of Canada. Accessed June 15, 2010. http://www.em.gov.bc. ca/EEC/Strategy/BCECE/Documents/Standby\%20Power
$\% 20$ Regulatory $\% 20$ Impact $\% 20$ Statement $\% 20$ Final.pdf.

[38] Varman, M., Mahlia, T. M. I., and Masjuki, H. H. 2006. "Method for Calculating Annual Energy Efficiency Improvement of TV Sets." Energy Policy 34 (15): 2429-32.

[39] Kaldellis, J. K., Zafirakis, D., and Kondili, E. 2009. "Contribution of Lignite in the Greek Electricity Generation: Review and Future Prospects." Fuel 88 (3): 475-89. 